\title{
Segregation of signaling proteins as prognostic predictors for local recurrence and distant metastasis in hepatocellular carcinoma
}

\author{
CHAU-TING YEH ${ }^{1,2}$, YA-HUI HUANG ${ }^{1}$, KUNG-HAO LIANG $^{1}$, MING-LING CHANG ${ }^{1}$, CHAO-WEI HSU $^{1}$, \\ YI-CHENG CHEN ${ }^{1}$, TSE-CHING $\mathrm{CHEN}^{3}$, TA-SEN YEH ${ }^{4}$ and WEI-CHEN LEE ${ }^{4}$ \\ ${ }^{1}$ Liver Research Center, Department of Hepato-Gastroenterology, Chang Gung Memorial Hospital, Taipei 105; \\ ${ }^{2}$ Molecular Medicine Research Center, Chang Gung University, Kwei-Shan County, Taoyuan 333; \\ ${ }^{3}$ Department of Pathology and ${ }^{4}$ Division of General Surgery, Department of Surgery, \\ Chang Gung Medical Center, Taipei 105, Taiwan, R.O.C.
}

Received September 25, 2013; Accepted November 8, 2013

DOI: $10.3892 /$ ijo.2013.2198

\begin{abstract}
Postoperative recurrence of hepatocellular carcinoma (HCC) is presented as local recurrence (LR) or extrahepatic metastasis (EHM). Recent studies indicated that EHM requires additional cellular alterations. This study aimed to examine the clinical and molecular prognostic predictors of these two events. HCC patients (289) [training cohort $(n=160)$ and verification cohort $(n=129)$ ] receiving surgical resection of hepatomas were included. The expression levels of six signaling molecules were quantitatively assessed for prognostic analysis. Clustering analysis revealed similar expression profiles between cancer $(\mathrm{T})$ and non-cancer $(\mathrm{N})$ liver tissues in the same individuals. Univariate analysis showed that phosphorylated mammalian target of rapamycin (mTOR)-T was associated with LR-free survival $(\mathrm{P}=0.002)$, whereas extracellular signal-related kinase (ERK2)-T $(\mathrm{P}=0.005)$, AKT-T $(\mathrm{P}=0.001)$ and glycogen synthase kinase $(\mathrm{GSK})-\mathrm{T} / \mathrm{N}$ ratio $(\mathrm{P}=0.008)$ were associated with EHM-free survival. When clinical predictors were added for multivariate analysis, only prolonged prothrombin time $(\mathrm{P}=0.003)$ and tumor number $(\mathrm{P}=0.031)$ was independently associated with LR-free survival, whereas age $(\mathrm{P}=0.019)$, creatinine levels $(\mathrm{P}=0.001)$ and AKT-T $(\mathrm{P}=0.004)$ were associated with EHM-free survival. These factors were further examined in the verification cohort. In conclusion, postoperative LR and EHM in HCC were associated with separable sets of clinical and molecular predictors.
\end{abstract}

\section{Introduction}

Hepatocellular carcinoma (HCC) is the fifth most common solid cancer and the third most common cancer-related death

Correspondence to: Dr Chau-Ting Yeh, Liver Research Center, Chang Gung Memorial Hospital, 199 Tung Hwa North Road, Taipei 105, Taiwan, R.O.C.

E-mail: chautingy@gmail.com

Key words: hepatocellular carcinoma, signaling proteins, local recurrence, extrahepatic metastasis, survival in the world (1). HCC is of multifactorial origin. The three most frequent causes are chronic hepatitis B virus (HBV) infection, chronic hepatitis $\mathrm{C}$ virus (HCV) infection and alcoholic liver disease $(2,3)$. Other important risk factors include old age, male gender, chronic liver diseases of other etiologies, aflatoxin exposure, diabetes and liver cirrhosis (4-6). Because of the complex etiologies, the major molecular pathways responsible for liver cancer development remain elusive. Recent molecular and genomic studies have led to the concept that hepatocarcinogenesis involves not only multiple steps of molecular events but also heterogeneous cellular pathways (7).

One important approach for the researchers to understand the molecular processes linking to liver cancer cell growth is to identify prognostic molecular markers in patients receiving total resection of HCC. After standard procedure of surgical resection, no grossly detectable tumor should remain. These patients form a relatively homogeneous group in clinical aspects and the periods of time to subsequent cancer recurrence should reflect the growth behavior of the HCC cells. Thus, the molecule with its expression level capable of predicting postoperative survival is considered tightly associated with hepatocarginogenesis and is believed to be a candidate of anticancer targets. Based on this principle, many molecules have been identified, such as proline-directed protein kinase $\mathrm{F}(\mathrm{A})$, MKP-1 (a mitogen-activated protein kinase), vascular endothelial growth factor, proliferating cell nuclear antigen, p53, TA (tissue factor), cytokeratin-19, telomerase activity and interleukin-10 (8-16).

In almost all of these studies, HCC recurrence was defined as development of either local recurrence (LR) or extrahepatic metastasis (EHM). Thus, no clear distinction was made between these two clinical conditions when calculating the recurrence-free survival. However, in our clinical experience, LR and EHM could occur in independent time sequence. In many patients, LR could progress to a very advanced stage characterized by a huge tumor involving both lobes of liver, portal vein thrombosis, invasion to large vessels, and decompensated liver function, yet EHM was still undetectable. On the other hand, in some patients, EHM developed during postoperative follow-up in the absence of LR. Recent studies 
indicated that development of EHM involved particular molecular events linked to epithelial to mesenchymal transition $(17,18)$. Therefore, in this study, we aimed to investigate whether LR and EHM involved different and separable molecular and clinical predictors.

\section{Patients and methods}

Patients. This study was conducted under the approval of the institutional review board, Chang Gung Medical Council, Taiwan. In total, 289 pairs of cancer (denoted as '-T') and non-cancer (denoted as '-N') liver tissues were retrieved from Tissue Bank, Chang Gung Medical Cancer for our study. Of these tissues, 160 pairs were obtained from January, 2002 to December, 2005 (as the training cohort) and 129 pairs were obtained from January, 2006 to December, 2007 (as the verification cohort). All tissues were frozen to $-70^{\circ} \mathrm{C}$ immediately after surgical resection until used. Clinicopathological data were reviewed including gender, age, presence of liver cirrhosis, alcohol usage, Edmondson's histologic grade, microvascular invasion, macrovascular invasion, presence of tumor capsule, number of tumors, largest tumor size, presence of ascites upon surgery, $\alpha$-fetoprotein (AFP), albumin, bilirubin, prothrombin time, creatinine, aspartate aminotransferase (AST), alanine aminotransferase (ALT), date of surgical resection, date of LR, date of EHM and date of last follow-up or HCC related death. Patients with main portal vein thrombosis were excluded from surgical management in this medical center. Minor portal vein invasion discovered during or after surgery was categorized as macrovascular invasion.

Diagnosis of HCC was made by one of the following criteria: echo-guided liver biopsy, fine needle aspiration cytology, high AFP level (>200 ng/ml) plus at least one dynamic imaging study (dynamic computed tomography or magnetic resonance imaging), or one dynamic imaging study plus angiography (if AFP $<200 \mathrm{ng} / \mathrm{ml}$ ). Tumors were completely removed during surgical procedure, with a safety-margin of $>1 \mathrm{~cm}$. The patients were followed postoperatively by ultrasonography, chest X-ray, AFP, and blood biochemistry every 1-3 months in the first year and every 3-6 months thereafter. Suspicious tumors were further studied by computed tomography or magnetic resonance imaging. LR was established by use of the aforementioned criteria for HCC diagnosis. EHM was confirmed by tumor biopsy, aspiration cytology, computed tomography or magnetic resonance imaging. The choice of study was dependent upon the tumor locations and the condition of patients.

HBV surface antigen (HBsAg) was measured by radioimmunoassay (Ausria-II, HBsAg-RIA; Abbott Laboratories, North Chicago, IL, USA). Anti-HCV antibody was measured by a third-generation enzyme immunoassay (HCV EIA III; Abbott Laboratories).

Western blot analysis. To assess the expression levels of a growth regulatory signaling molecule in liver tissues, western blot analysis was performed. The following antibodies were used: rabbit anti-phosphatase and tension homolog (PTEN) antibody (Cell Signaling Technology, Inc., Beverly, MA, USA); rabbit anti-phospho-PTEN (ser380) antibody (Cell Signaling Technology); rabbit anti-AKT antibody (Abcam
Inc., Cambridge, UK); rabbit anti-phospho-AKT (Ser473) antibody (Cell Signaling Technology); rabbit anti-glycogen synthase kinase GSK)-3 $\beta$ antibody (Imgenex Corp., San Diego, CA, USA); rabbit anti-phospho-GSK-3 $\beta$ (Ser9) antibody (Cell Signaling Technology); rabbit anti-extracellular signal-related kinase (ERK) $1 / 2$ antibody (Cell Signaling Technology); rabbit anti-phospho-ERK 1/2 (Thr202/Tyr204) antibody (Cell Signaling Technology); rabbit anti-mammalian target of rapamycin (mTOR) antibody (Abcam); rabbit anti-phospho-mTOR (ser2448) antibody (Cell Signaling Technology). Following western blotting, the expression levels were assessed by a densitometer. The abundance of a protein expressed in HepG2 cells was assigned as $1 \mathrm{HepG} 2$ unit (HU). The expression level of a protein in liver tissue was calculated as its relative abundance compared to the corresponding level in HepG2 cells.

Cell culture. HepG2 cells were maintained in minimal essential medium containing $10 \%$ fetal bovine serum. The cells were grown to $90 \%$ confluence and harvested for western blot analysis. The expression levels of signaling proteins detected in HepG2 cells were used as a reference for comparison.

Protein clustering and heatmap presentation. The protein levels assessed by western blotting and normalized against their corresponding levels in HepG2 cells were subjected for $\log 10$ transformation. A comparison of the means of the $\log 10$ transformed values across groups was done by two sample t-test with unequal variance. All P-values were two tailed. Protein values were clustered by a bottom-up hierarchical clustering method performed by the Cluster 3.0 software (19). Similarities of protein profiles across the clinical samples were gauged by their Euclidean distances of the normalized protein levels. Heatmaps were used to visualize the result of clustering, where protein biomarkers are sorted by their similarity in normalized levels. A spectrum of red to green was used to visualize the relative ups and downs to the average levels of the good-prognosis group of patients. The heatmaps were generated by the Treeview software (20).

Statistical analysis. LR-free survival was calculated from the date of surgery to the date of LR or last follow-up. EHM-free survival was calculated from the date of surgery to the date of EHM or last follow-up. Overall survival was calculated from the date of surgery to the date of death or last follow-up. Univariate analysis was performed by the Kaplan-Meier method and the log-rank test was used to compare the survival curves between groups. To obtain a suitable cutoff value for clinical application, the principle of minimal P-value approach was adopted (21). Accordingly, experimental univariate analysis was performed to assess the difference of LR-free survival using a series of 5 cutoff values for each protein expression level. The cutoff resulting in the smallest P-value was used for further calculation. The 5 experimental cutoffs were calculated using the following equation: The smallest value $+n / 6 \times$ (The largest value - The smallest value); $n=1-5$.

The Cox proportional hazard model was used to identify independent clinicopathological and signaling molecular factors associated with postoperative survival. Statistical analysis was conducted by the use of SPSS (version 13.0). 
Table I. Basic clinical characterization of HCC patients included.

\begin{tabular}{|c|c|c|c|}
\hline \multirow[b]{2}{*}{ Clinical parameters } & \multicolumn{2}{|c|}{ Gender } & \multirow[b]{2}{*}{ P-value } \\
\hline & Female $(n=41)$ & Male $(n=119)$ & \\
\hline Age (years) & $57.6 \pm 13.1$ & $55.3 \pm 15.5$ & 0.360 \\
\hline Cirrhosis & $20(48.8 \%)$ & $57(47.9 \%)$ & 0.933 \\
\hline HBsAg-positive & $22(53.7 \%)$ & $88(73.9 \%)$ & 0.026 \\
\hline Anti-HCV-positive & $19(46.3 \%)$ & $25(21.0 \%)$ & 0.003 \\
\hline \multicolumn{4}{|l|}{ Tumor number } \\
\hline 1 & $29(70.7 \%)$ & $75(63.0 \%)$ & $0.482^{\mathrm{a}}$ \\
\hline 2 & 6 & 18 & \\
\hline 3 & 5 & 19 & \\
\hline 4 & 1 & 7 & \\
\hline Size (diameter, $\mathrm{cm}$ ) & $6.9 \pm 4.8$ & $6.8 \pm 4.7$ & 0.906 \\
\hline Ascites & $1(2.4 \%)$ & $13(10.9 \%)$ & 0.119 \\
\hline$\alpha$-fetoprotein (ng/ml) & $45(3-327500)^{\mathrm{b}}$ & $52(0-286980)^{\mathrm{b}}$ & $0.717^{\mathrm{c}}$ \\
\hline Albumin (g/dl) & $3.6 \pm 0.6$ & $3.8 \pm 0.6$ & 0.058 \\
\hline Bilirubin (mg/dl) & $1.1 \pm 1.0$ & $1.3 \pm 1.8$ & 0.265 \\
\hline Prothrombin time (sec) & $12.4 \pm 1.9$ & $12.4 \pm 1.3$ & 0.992 \\
\hline Creatinine (mg/dl) & $1.0 \pm 0.8$ & $1.2 \pm 0.9$ & 0.163 \\
\hline $\operatorname{AST}(\mathrm{U} / \mathrm{l})$ & $101.7 \pm 109.6$ & $87.5 \pm 117.5$ & 0.483 \\
\hline ALT (U/l) & $68.8 \pm 67.0$ & $81.9 \pm 109.6$ & 0.367 \\
\hline Alcoholism & $4(9.8 \%)$ & $41(34.5 \%)$ & 0.005 \\
\hline
\end{tabular}

${ }^{\mathrm{a}}$ Comparison between patients with tumor number $=1$ and those with tumor number $>1 .{ }^{\mathrm{b}}$ Median (range). ${ }^{\mathrm{c}}$ Mann-Whitney test.

\section{Results}

Basic clinicopathological data for the two cohorts of HCC patients. In this study 289 pairs of HCC tissues were included. Of them, 160 pairs were assigned as the training cohort to identify significant predictors, while 129 pairs were designated as the verification cohort to examine the usefulness of the candidate predictors. These two cohorts of patients were collected from different periods of time (see Materials and methods) so that the verified predictors could be more reliable when used in the future. The basic clinicopathological data of the training cohort of patients are listed in Table I. In these HCC patients, more males were included. More HBV infected patients $(\mathrm{P}=0.026)$ and more alcoholic patients $(\mathrm{P}=0.005)$ were found in males, while more HCV infected patients $(\mathrm{P}=0.003)$ were found in females. The basic clinicopathological data of the verification cohort of patients are given in Table II. Interestingly, the male preference for HBV infection and female preference for HCV infection disappeared in the verification cohort, while more male alcoholic patients $(\mathrm{P}<0.001)$ were still observed. Additionally, a borderline $(\mathrm{P}=0.043)$ significantly higher AFP level was found in the female HCC patients in the verification cohort. The differential etiology distribution between the two cohorts suggested a likely change of HCC epidemiology over time, since the two cohorts were collected in different periods of time.
Clustering analysis revealed similar expression profiles between the cancer and non-cancer tissues from the same HCC patients. All cancer and non-cancer tissues were submitted for western blot analysis to assess the expression levels of the total and phosphorylated forms of six signaling proteins (Fig. 1). The loading amounts were monitored by use of actin levels. All expression levels were calculated as the HepG2 unit (HU) by assigning the expression level in HepG2 cells as $1 \mathrm{HU}$. The ERK1 (p44) and ERK2 (p42) levels were calculated separately because they were well-distinguishable. On the other hand, the GSK-3 $\alpha$ and $\beta$ could not be well separated using the antiGSK-3 $\beta$ and the anti-phospho-GSK-3 $\beta$ antibodies. Two to three bands migrating between the two expected positions in different HCC tissues were observed. In this study, we thus calculated the total GSK-3 ( $\alpha$ plus $\beta$ ) levels. The phosporylated ratios (PR) of the signaling proteins were calculated by dividing the relative abundance of phosphorylated forms by the relative abundance of the total forms. The cancer/non-cancer (denoted as ' $\mathrm{T} / \mathrm{N}$ ') ratios of all forms for all proteins were also calculated.

In terms of $\mathrm{HCC}$ recurrence, three groups of patients with representative clinical courses could be identified. Of the 160 patients, 18 patients who had no tumor recurrence throughout the follow-up periods ( $\geq 3$ years) were considered the good prognosis group, 21 patients who had LR within 1 year (but not EHM) were assigned as the LR group, and 14 patients who had EHM within 1 year were assigned as the metastasis 
Table II. Basic clinical characterization of HCC patients included for verification.

\begin{tabular}{|c|c|c|c|}
\hline \multirow[b]{2}{*}{ Clinical parameters } & \multicolumn{2}{|c|}{ Gender } & \multirow[b]{2}{*}{ P-value } \\
\hline & Female (n=22) & Male $(\mathrm{n}=107)$ & \\
\hline Age (years) & $56.1 \pm 13.8$ & $55.9 \pm 13.1$ & 0.660 \\
\hline Cirrhosis & $16(72.7 \%)$ & $75(70.1 \%)$ & 0.999 \\
\hline HBsAg-positive & $15(68.2 \%)$ & $86(80.4 \%)$ & 0.327 \\
\hline Anti-HCV-positive & $11(50.0 \%)$ & $31(29.0 \%)$ & 0.096 \\
\hline \multicolumn{4}{|l|}{ Tumor number } \\
\hline 1 & $6(27.3 \%)$ & $33(30.8 \%)$ & $0.938^{\mathrm{a}}$ \\
\hline 2 & 9 & 43 & \\
\hline 3 & 5 & 20 & \\
\hline 4 & 2 & 11 & \\
\hline Size (diameter, $\mathrm{cm}$ ) & $4.9 \pm 4.4$ & $5.9 \pm 4.0$ & 0.296 \\
\hline Ascites & $3(13.6 \%)$ & $12(11.2 \%)$ & 0.964 \\
\hline$\alpha$-fetoprotein (ng/ml) & $231.5(3.5-443209)^{\mathrm{b}}$ & $33.2(2.0-45164)^{\mathrm{b}}$ & $0.043^{\mathrm{c}}$ \\
\hline Albumin $(\mathrm{g} / \mathrm{dl})$ & $4.2 \pm 0.4$ & $3.9 \pm 0.6$ & 0.213 \\
\hline Bilirubin (mg/dl) & $0.9 \pm 0.3$ & $1.5 \pm 1.9$ & 0.089 \\
\hline Prothrombin time (sec) & $11.5 \pm 0.9$ & $12.5 \pm 1.7$ & 0.126 \\
\hline Creatinine (mg/dl) & $1.0 \pm 0.4$ & $1.1 \pm 0.3$ & 0.745 \\
\hline $\operatorname{AST}(\mathrm{U} / \mathrm{l})$ & $54.6 \pm 39.9$ & $68.7 \pm 105.9$ & 0.312 \\
\hline $\operatorname{ALT}(\mathrm{U} / \mathrm{l})$ & $59.7 \pm 54.7$ & $89.9 \pm 165.2$ & 0.217 \\
\hline Alcoholism & $0(0 \%)$ & $42(39.3 \%)$ & $<0.001$ \\
\hline
\end{tabular}

${ }^{\mathrm{a}}$ Comparison between patients with tumor number $=1$ and those with tumor number $>1 .{ }^{\mathrm{b}}$ Median (range). ${ }^{\mathrm{c}}$ Mann-Whitney test.

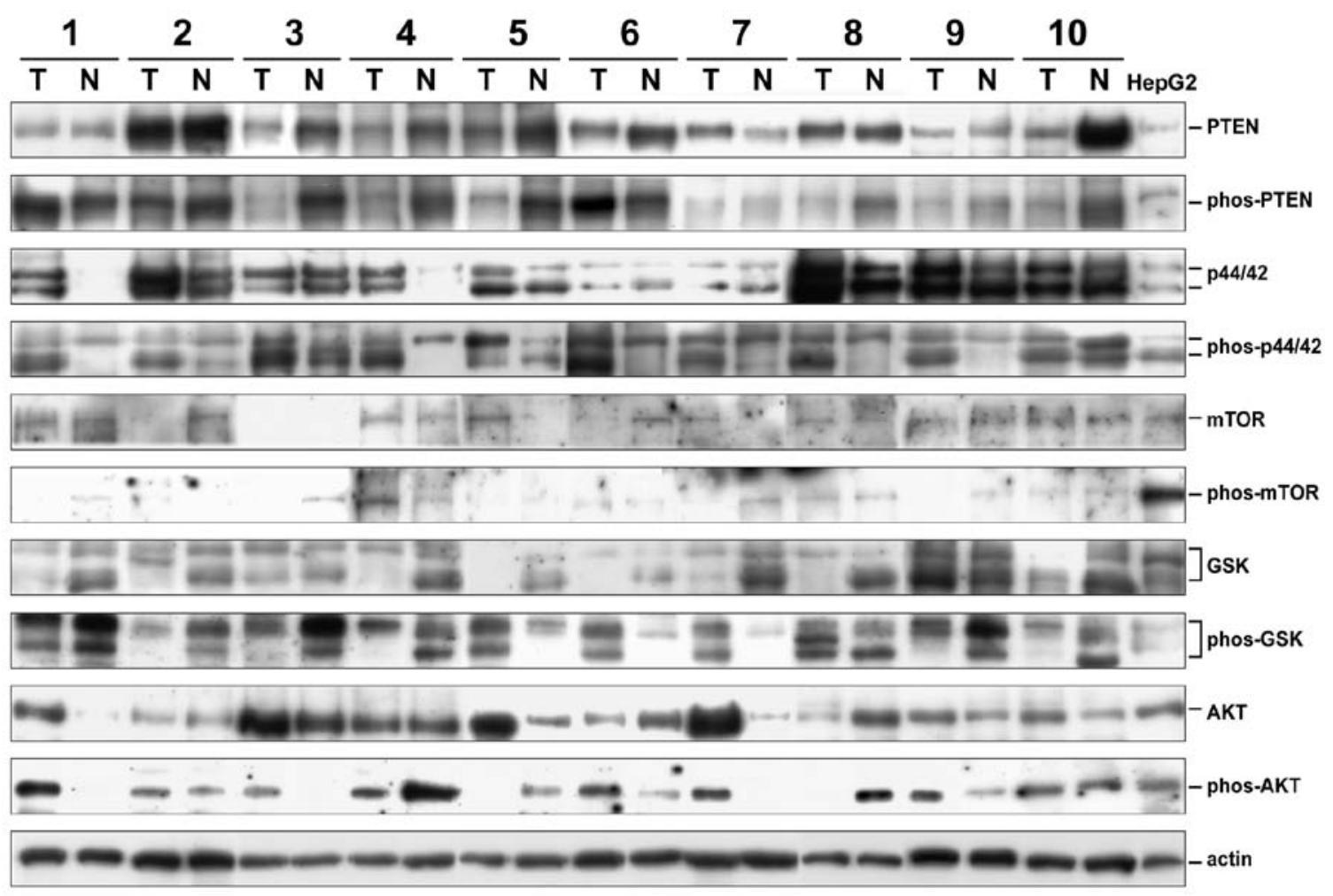

Figure 1. Western blot analysis of the expression levels of signaling proteins in the cancer $(\mathrm{T})$ and non-cancer $(\mathrm{N}) \mathrm{HCC}$ tissues. The corresponding expression levels in HepG2 cells were used for calculation of the relative abundances of these proteins. Actin levels were used as loading controls. 

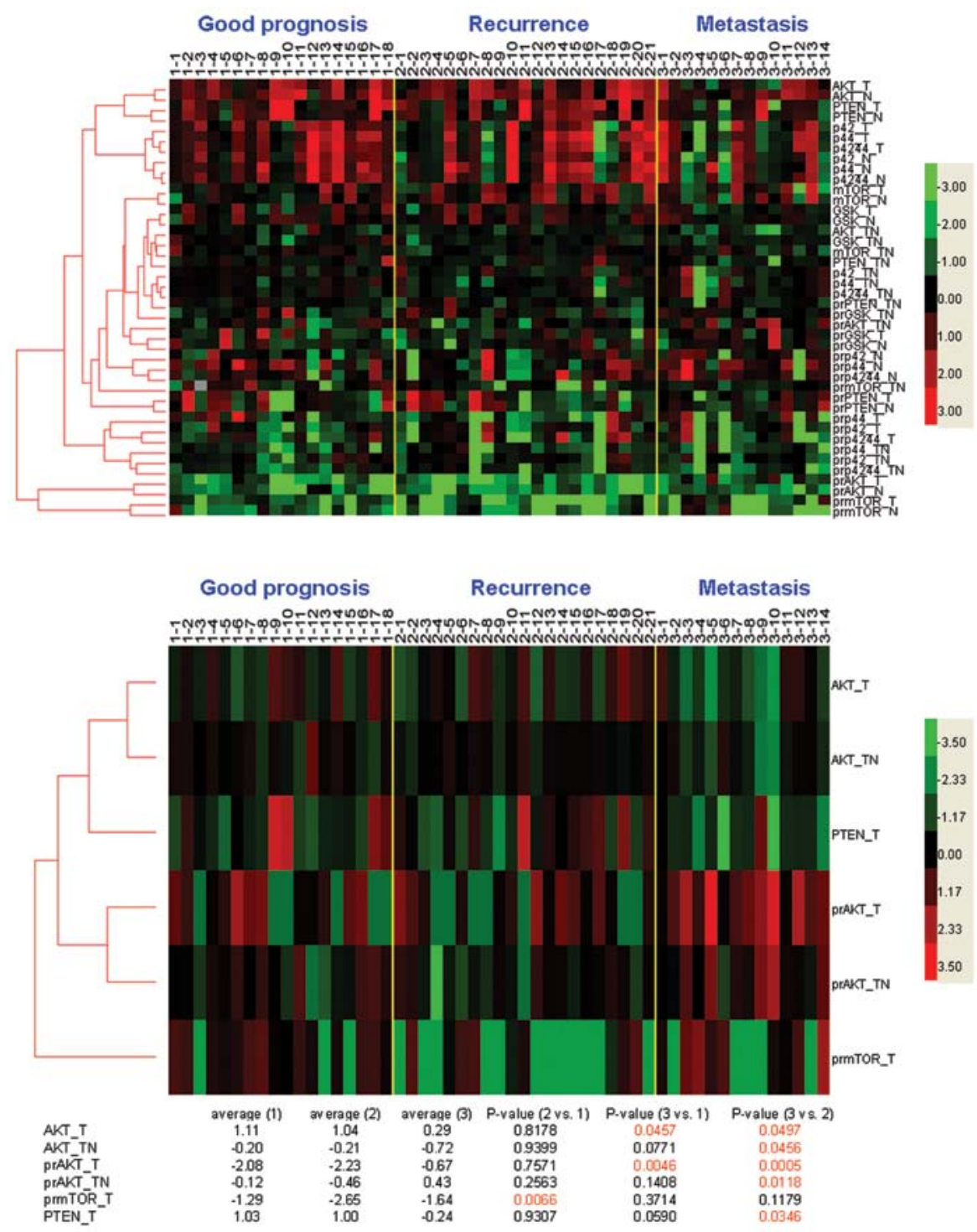

Figure 2. Heatmap and clustering analysis of three representative groups of HCC patients. Representative patients with (1) good prognosis (n=18), (2) postoperative local recurrence $(n=21)$ and (3) postoperative metastasis $(n=14)$ were included. The calculated expression levels of all signaling proteins in this study were $\log 10$-transformed before subjected for heatmap construction. The clustering tree constructed by assessing the Euclidean distances of the expression levels were depicted to the left of the upper panel. The means of the $\log 10$-transformed value were compared across the three groups. Molecular factors with statistical differences $(\mathrm{P}<0.05)$ in their expression levels are listed at the bottom. A heatmap of these factors were also constructed (lower panel).

group. A heatmap was constructed for assessment (Fig. 2, upper panel). Clustering analysis showed that the expression profiles between the cancer (-T) and non-cancer (-N) tissues were similar (clustered together) in most of the markers, while the expression profiles between different signaling proteins were distantly related (Fig. 2, upper panel). To understand whether difference of protein expression existed between the three types of HCC patients, the mean expression levels after $\log 10$ transformation were compared (Fig. 2, bottom). Statistical analysis showed that the means of the $\log 10$ transformed PR-mTOR-T values were significantly different between the good prognosis and LR group but not between the good prognosis and metastasis group (Fig. 2, bottom). On the other hand, the means of the $\log 10$-transformed AKT-T and PR-AKT-T values were significantly different between the good prognosis and metastasis group but not between the good prognosis and LR group. Furthermore, significant differences were observed for the means of the log10-transformed AKT-T, AKT-T/N, PR-AKT-T, PR-AKT-T/N, and PTEN-T values between the LR and metastasis groups.

Univariate analysis of the signaling proteins as predictors of LR and EHM. By use of the principle of minimal P-value method (see Materials and methods), the best cutoffs for all expression levels were used in calculating the LR-free survival association (Table III). After corrected by the Bonferroni method, borderline significance of the LR-free survival difference was found in ERK1-T, ERK2-T, ERK(1+2)-T, GSK-T/N, PR-ERK1-N, PR-PTEN-T/N and PR-ERK2-T/N levels. Only higher PR-mTOR-T level $(\geq 0.50)$ was considered significantly associated with a better LR-free survival.

On the other hand, borderline significance of the EHM-free survival difference was found in GSK-T, PTEN-T, PTEN-T/N, ERK1-T/N, ERK(1+2)-T/N, and PR-AKT-N levels (Table IV), 
Table III. Univariate analysis of signaling molecule expression levels as predictors for LR-free survival in postoperative HCC patients.

A, Protein expression levels in HCC tissues

\begin{tabular}{|c|c|c|c|c|}
\hline Parameter & $\begin{array}{l}\text { Expression } \\
\text { levels }\end{array}$ & $\begin{array}{l}\text { No. of } \\
\text { patients }\end{array}$ & $\begin{array}{l}\text { Mean disease-free survival } \\
(95 \% \mathrm{CI})\end{array}$ & $\begin{array}{c}\text { Log-rank } \\
\text { P-value }\end{array}$ \\
\hline \multicolumn{5}{|c|}{ 1. Non-cancer parts ${ }^{\mathrm{a}}$} \\
\hline \multirow[t]{2}{*}{ GSK } & $<16.5 \mathrm{HU}$ & 135 & $40.5(30.9-50.2)$ & \\
\hline & $\geq 16.5 \mathrm{HU}$ & 21 & $27.2(11.8-42.7)$ & 0.401 \\
\hline \multirow[t]{2}{*}{ PTEN } & $<3.85 \mathrm{HU}$ & 82 & $38.6(25.9-51.3)$ & \\
\hline & $\geq 3.85 \mathrm{HU}$ & 73 & $37.2(26.7-47.8)$ & 0.791 \\
\hline \multirow[t]{2}{*}{ mTOR } & $<0.40 \mathrm{HU}$ & 36 & $31.4(22.1-40.8)$ & \\
\hline & $\geq 0.40 \mathrm{HU}$ & 120 & $38.8(28.5-49.0)$ & 0.985 \\
\hline \multirow[t]{2}{*}{ p44 (ERK1) } & $<10.0 \mathrm{HU}$ & 87 & $40.9(28.6-53.1)$ & \\
\hline & $\geq 10.0 \mathrm{HU}$ & 68 & $34.3(23.3-45.3)$ & 0.400 \\
\hline \multirow[t]{2}{*}{ p42 (ERK2) } & $<45.5 \mathrm{HU}$ & 130 & $40.4(30.7-50.0)$ & \\
\hline & $\geq 45.5 \mathrm{HU}$ & 25 & $23.4(14.2-32.6)$ & 0.382 \\
\hline \multirow[t]{2}{*}{ ERK $(1+2)$} & $<16.0 \mathrm{HU}$ & 102 & $40.9(29.4-52.4)$ & \\
\hline & $\geq 16.0 \mathrm{HU}$ & 53 & $33.6(21.8-45.4)$ & 0.480 \\
\hline \multirow[t]{2}{*}{ AKT } & $<200 \mathrm{HU}$ & 133 & $36.4(27.2-45.6)$ & \\
\hline & $\geq 200 \mathrm{HU}$ & 23 & $49.3(28.8-69.8)$ & 0.336 \\
\hline \multicolumn{5}{|c|}{ 2. Cancer parts ${ }^{\mathrm{a}}$} \\
\hline \multirow[t]{2}{*}{ GSK } & $<8.50 \mathrm{HU}$ & 126 & $37.9(28.9-46.9)$ & \\
\hline & $\geq 8.50 \mathrm{HU}$ & 30 & $35.6(17.2-54.0)$ & 0.661 \\
\hline \multirow[t]{2}{*}{ PTEN } & $<3.00 \mathrm{HU}$ & 87 & $35.3(24.4-46.2)$ & \\
\hline & $\geq 3.00 \mathrm{HU}$ & 68 & $40.0(27.7-52.3)$ & 0.778 \\
\hline \multirow[t]{2}{*}{ mTOR } & $<0.33 \mathrm{HU}$ & 38 & $23.3(14.4-32.2)$ & \\
\hline & $\geq 0.33 \mathrm{HU}$ & 118 & $41.4(31.2-51.5)$ & 0.075 \\
\hline \multirow[t]{2}{*}{ p44 (ERK1) } & $<148.5 \mathrm{HU}$ & 131 & $41.1(31.7-50.5)$ & \\
\hline & $\geq 148.5 \mathrm{HU}$ & 24 & $15.8(6.4-25.1)$ & $0.027^{\mathrm{e}}$ \\
\hline \multirow[t]{2}{*}{ p42 (ERK2) } & $<0.60 \mathrm{HU}$ & 40 & $20.8(12.3-29.3)$ & \\
\hline & $\geq 0.60 \mathrm{HU}$ & 115 & $42.3(32.2-52.4)$ & $0.025^{\mathrm{e}}$ \\
\hline \multirow[t]{2}{*}{ ERK (1+2) } & $<48.0 \mathrm{HU}$ & 128 & $42.9(32.8-52.9)$ & \\
\hline & $\geq 48.0 \mathrm{HU}$ & 27 & $17.5(10.0-25.1)$ & $0.011^{\mathrm{e}}$ \\
\hline \multirow[t]{2}{*}{ AKT } & $<1.0 \mathrm{HU}$ & 142 & $38.5(29.7-47.3)$ & \\
\hline & $\geq 1.0 \mathrm{HU}$ & 11 & $28.0(10.4-45.6)$ & 0.951 \\
\hline \multicolumn{5}{|c|}{ 3. Cancer parts/non-cancer parts ${ }^{\mathrm{b}}$} \\
\hline \multirow[t]{2}{*}{ GSK } & $<0.65$ & 61 & $25.0(16.4-33.5)$ & \\
\hline & $\geq 0.65$ & 95 & $47.8(35.4-60.1)$ & $0.035^{\mathrm{e}}$ \\
\hline \multirow[t]{2}{*}{ PTEN } & $<0.52$ & 33 & $37.6(21.4-53.8)$ & \\
\hline & $\geq 0.52$ & 122 & $38.7(28.9-48.6)$ & 0.907 \\
\hline \multirow[t]{2}{*}{ mTOR } & $<1.04$ & 87 & $35.8(23.9-47.8)$ & \\
\hline & $\geq 1.04$ & 69 & $39.6(28.9-50.2)$ & 0.194 \\
\hline \multirow[t]{2}{*}{ p44 (ERK1) } & $<2.50$ & 114 & $38.6(28.1-49.1)$ & \\
\hline & $\geq 2.50$ & 41 & $36.8(22.3-51.2)$ & 0.877 \\
\hline \multirow[t]{2}{*}{ p42 (ERK2) } & $<1.80$ & 120 & $41.7(31.6-51.8)$ & \\
\hline & $\geq 1.80$ & 35 & $25.8(12.9-38.8)$ & 0.223 \\
\hline \multirow[t]{2}{*}{ ERK $(1+2)$} & $<1.34$ & 111 & $41.7(31.1-52.4)$ & \\
\hline & $\geq 1.34$ & 44 & $29.4(16.9-41.0)$ & 0.306 \\
\hline \multirow[t]{2}{*}{ AKT } & $<0.88$ & 94 & $34.7(24.8-44.6)$ & \\
\hline & $\geq 0.88$ & 62 & $40.9(27.3-54.5)$ & 0.333 \\
\hline
\end{tabular}


Table III. Continued.

$\mathrm{B}$, Relative ratios of phosphorylated protein expression levels in HCC tissues

\begin{tabular}{cccc}
\hline Parameter & $\begin{array}{c}\text { Expression } \\
\text { levels }\end{array}$ & $\begin{array}{c}\text { No. of } \\
\text { patients }\end{array}$ & $\begin{array}{c}\text { Mean disease-free survival } \\
(95 \% \text { CI })\end{array}$ \\
\hline
\end{tabular}

1. Non-cancer parts ${ }^{\mathrm{c}}$

PR-GSK

$\begin{array}{rr}<0.50 & 77 \\ \geq 0.50 & 76 \\ <1.87 & 10 \\ \geq 1.87 & 59 \\ <0.20 & 94 \\ \geq 0.20 & 59 \\ <0.10 & 20 \\ \geq 0.10 & 13 \\ <2.30 & 10 \\ \geq 2.30 & 46 \\ <3.50 & 92 \\ \geq 3.50 & 62 \\ <0.01 & 34 \\ \geq 0.01 & 11\end{array}$

$39.1(26.9-51.3)$

PR-PTEN

76

36.6 (25.0-48.2)

0.824

PR-mTOR

59

$40.1(29.9-50.3)$

$33.0(20.4-45.7)$

0.284

36.2 (25.9-46.4)

$43.9(28.8-59.1)$

0.550

PR-p44 (ERK1)

20

$16.2(5.5-26.8)$

$40.3(31.1-49.5)$

$43.0(32.0-53.9)$

PR-p42 (ERK2)

104

26.8 (14.8-38.8)

$0.031^{\mathrm{e}}$

PR-ERK (1+2)

92

40.7 (28.9-52.4)

33.7 (22.5-45.0)

0.215

PR-AKT

34

$57.2(36.5-77.8)$

$33.3(24.7-42.0)$

0.720

0.140

2. Cancer parts ${ }^{\mathrm{c}}$

PR-GSK

$<0.60$

$38.9(27.4-50.3)$

PR-PTEN

$\geq 0.60$

84

36.7 (24.4-48.9)

0.814

$<0.20$

$41.1(27.3-54.8)$

$\geq 0.20$

$37.2(26.6-47.8)$

$24.0(15.2-32.7)$

PR-mTOR

$<0.50$

$49.8(37.3-62.2)$

PR-p44 (ERK1)

$\geq 0.50$

$43.2(30.4-56.1)$

$\geq 0.89 \quad 72$

PR-p42 (ERK2)

$<2.40$

$31.2(22.4-40.1)$

$42.4(31.8-53.0)$

$32.2(17.3-47.0)$

$41.6(31.2-52.0)$

PR-ERK (1+2)

$\begin{array}{lr}\geq 2.40 & 38 \\ <2.50 & 102\end{array}$

$\geq 2.50 \quad 42$

PR-AKT

$<0.63$

$28.4(14.7-42.1)$

37.5 (28.0-46.9)

$41.7(23.1-60.2)$

0.595

$0.002^{\mathrm{f}}$

$\geq 0.63 \quad 27$

$45.4(32.2-58.5)$

$<0.95 \quad 74$

$\geq 0.95 \quad 78$

$31.8(21.5-42.1)$

$44.2(33.6-54.9)$

$21.1(13.1-29.0)$

0.189

$\geq 1.16 \quad 47$

$35.6(26.3-44.9)$

$<2.48 \quad 97$

$\geq 2.48 \quad 36$

$54.2(27.8-80.5)$

0.720

0.455

$<0.61 \quad 96$

$33.5(24.7-42.4)$

$52.3(33.6-71.1)$

$32.2(23.7-40.7)$

$<1.50 \quad 114$

$\geq 1.50 \quad 29$

$62.1(40.5-83.6)$

$34.3(25.3-42.2)$

$\begin{array}{lr}<0.84 & 111 \\ \geq 0.84 & 35\end{array}$

52.3 (32.7-71.9)

0.341

0.854

$<1.10$

101

$33.4(24.9-42.0)$

$\geq 1.10$

49

45.4 (28.1-62.7)

$0.012^{\mathrm{e}}$

0.228

0.190

$0.027^{\mathrm{e}}$

0.170

0.322

${ }^{a}$ The expression level of a signaling protein in HepG2 cells was assigned as $1 \mathrm{HU}$ (HepG2 unit). The expression level of the protein in liver

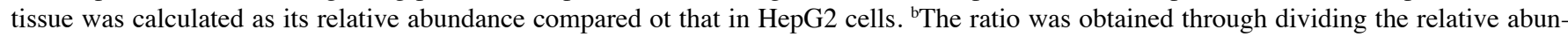
dance of protein in the cancer tissue by the relative abundance of protein in the non-cancer tissue. ${ }^{\circ}$ The relative phosphorylated ratio (PR) was obtained through dividing the abundance of phosphorylated from by the abundance of the total form. ${ }^{\mathrm{d}}$ The ratio was obtained through dividing the relative phosphorylated ratio of protein in the cancer tissue by the relative phosphorylated ratio of protein in the non-cancer tissue. ${ }^{\mathrm{e} B e c a u s e}$ 5 cutoffs were experimentally tested for the smallest $\mathrm{P}$-value, $\mathrm{P}<0.05$ but $>0.01$ were considered borderline significant after Bonferroni correction of $\alpha$ error. ${ }^{\mathrm{f}} \mathrm{P}<0.01$ was considered statistical significant after Bonferroni correction. 
Table IV. Univariate analysis of signaling molecule expression levels as predictors for EHM-free survival in postoperative HCC patients.

A, Protein expression levels in HCC tissues

\begin{tabular}{|c|c|c|c|c|}
\hline Parameter & $\begin{array}{l}\text { Expression } \\
\text { levels }\end{array}$ & $\begin{array}{l}\text { No. of } \\
\text { patients }\end{array}$ & $\begin{array}{l}\text { Mean disease-free survival } \\
(95 \% \mathrm{CI})\end{array}$ & $\begin{array}{l}\text { Log-rank } \\
\text { P-value }\end{array}$ \\
\hline \multicolumn{5}{|c|}{ 1. Non-cancer parts ${ }^{\mathrm{a}}$} \\
\hline \multirow[t]{2}{*}{ GSK } & $<16.5 \mathrm{HU}$ & 135 & $91.2(78.4-104.0)$ & \\
\hline & $\geq 16.5 \mathrm{HU}$ & 21 & 118.7 (98.6-138.7) & 0.062 \\
\hline \multirow[t]{2}{*}{ PTEN } & $<3.85 \mathrm{HU}$ & 82 & $87.3(69.4-105.3)$ & \\
\hline & $\geq 3.85 \mathrm{HU}$ & 73 & $102.3(89.4-115.1)$ & 0.064 \\
\hline \multirow[t]{2}{*}{ mTOR } & $<0.40 \mathrm{HU}$ & 36 & $84.0(65.4-102.6)$ & \\
\hline & $\geq 0.40 \mathrm{HU}$ & 120 & $100.8(87.3-114.3)$ & 0.548 \\
\hline \multirow[t]{2}{*}{ p44 (ERK1) } & $<10.0 \mathrm{HU}$ & 87 & $96.6(79.1-114.2)$ & \\
\hline & $\geq 10.0 \mathrm{HU}$ & 68 & $93.3(78.9-107.6)$ & 0.924 \\
\hline \multirow[t]{2}{*}{ p42 (ERK2) } & $<45.5 \mathrm{HU}$ & 130 & $96.6(83.8-109.4)$ & \\
\hline & $\geq 45.5 \mathrm{HU}$ & 25 & $64.6(50.1-79.0)$ & 0.960 \\
\hline \multirow[t]{2}{*}{$\mathrm{ERK}(1+2)$} & $<16.0 \mathrm{HU}$ & 102 & $95.7(79.2-112.1)$ & \\
\hline & $\geq 16.0 \mathrm{HU}$ & 53 & $95.9(80.0-106.9)$ & 0.582 \\
\hline \multirow[t]{2}{*}{$\mathrm{AKT}$} & $<200 \mathrm{HU}$ & 133 & $93.6(80.4-106.9)$ & \\
\hline & $\geq 200 \mathrm{HU}$ & 23 & $108.7(90.7-126.7)$ & 0.205 \\
\hline \multicolumn{5}{|c|}{ 2. Cancer parts ${ }^{\mathrm{a}}$} \\
\hline \multirow[t]{2}{*}{ GSK } & $<8.50 \mathrm{HU}$ & 126 & $85.7(73.9-97.6)$ & \\
\hline & $\geq 8.50 \mathrm{HU}$ & 30 & $129.0(110.9 \sim 147.2)$ & $0.016^{\mathrm{e}}$ \\
\hline \multirow[t]{2}{*}{ PTEN } & $<3.00 \mathrm{HU}$ & 87 & $80.5(63.6-97.4)$ & \\
\hline & $\geq 3.00 \mathrm{HU}$ & 68 & $110.2(95.6-124.7)$ & $0.025^{\mathrm{e}}$ \\
\hline \multirow[t]{2}{*}{ mTOR } & $<0.33 \mathrm{HU}$ & 38 & $77.1(57.2-97.0)$ & \\
\hline & $\geq 0.33 \mathrm{HU}$ & 118 & $100.6(87.3-114.0)$ & 0.118 \\
\hline \multirow[t]{2}{*}{ p44 (ERK1) } & $<148.5 \mathrm{HU}$ & 131 & $100.0(87.5-122.4)$ & \\
\hline & $\geq 148.5 \mathrm{HU}$ & 24 & $47.8(32.3-63.3)$ & 0.082 \\
\hline \multirow[t]{2}{*}{ p42 (ERK2) } & $<0.60 \mathrm{HU}$ & 40 & $44.6(33.9-55.2)$ & \\
\hline & $\geq 0.60 \mathrm{HU}$ & 115 & $103.8(91.2-116.4)$ & $0.005^{\mathrm{f}}$ \\
\hline \multirow[t]{2}{*}{ ERK $(1+2)$} & $<48.0 \mathrm{HU}$ & 128 & $101.3(88.3-114.3)$ & \\
\hline & $\geq 48.0 \mathrm{HU}$ & 27 & $71.1(46.3-95.9)$ & 0.099 \\
\hline \multirow[t]{2}{*}{ AKT } & $<1.0 \mathrm{HU}$ & 142 & $98.8(86.6-111.1)$ & \\
\hline & $\geq 1.0 \mathrm{HU}$ & 11 & $25.9(10.2-41.6)$ & $0.001^{\mathrm{f}}$ \\
\hline \multicolumn{5}{|c|}{ 3. Cancer parts/non-cancer parts ${ }^{b}$} \\
\hline \multirow[t]{2}{*}{ GSK } & $<0.65$ & 61 & $76.5(59.8-93.1)$ & \\
\hline & $\geq 0.65$ & 95 & $107.1(92.4-121.7)$ & $0.008^{f}$ \\
\hline \multirow[t]{2}{*}{ PTEN } & $<0.52$ & 33 & $71.1(48.8-93.4)$ & \\
\hline & $\geq 0.52$ & 122 & $103.2(89.9-116.5)$ & $0.022^{\mathrm{e}}$ \\
\hline \multirow[t]{2}{*}{ mTOR } & $<1.04$ & 87 & $92.0(75.4-108.6)$ & \\
\hline & $\geq 1.04$ & 69 & $97.0(82.7-111.3)$ & 0.289 \\
\hline \multirow[t]{2}{*}{ p44 (ERK1) } & $<2.50$ & 114 & $101.4(86.7-116.0)$ & \\
\hline & $\geq 2.50$ & 41 & $77.5(57.4-97.6)$ & $0.039^{\mathrm{e}}$ \\
\hline \multirow[t]{2}{*}{ p42 (ERK2) } & $<1.80$ & 120 & $100.5(87.6-113.4)$ & \\
\hline & $\geq 1.80$ & 35 & $80.4(56.4-104.4)$ & 0.119 \\
\hline \multirow[t]{2}{*}{ ERK $(1+2)$} & $<1.34$ & 111 & $104.2(91.0-117.4)$ & \\
\hline & $\geq 1.34$ & 44 & $79.4(54.1-95.8)$ & $0.014^{\mathrm{e}}$ \\
\hline \multirow[t]{2}{*}{$\mathrm{AKT}$} & $<0.88$ & 94 & $90.1(76.7-103.5)$ & \\
\hline & $\geq 0.88$ & 62 & $98.9(78.7-119.1)$ & 0.689 \\
\hline
\end{tabular}


Table IV. Continued.

$\mathrm{B}$, Relative ratios of phosphorylated protein expression levels in HCC tissues

\begin{tabular}{|c|c|c|c|c|}
\hline Parameter & $\begin{array}{l}\text { Expression } \\
\text { levels }\end{array}$ & $\begin{array}{l}\text { No. of } \\
\text { patients }\end{array}$ & $\begin{array}{l}\text { Mean disease-free survival } \\
\qquad(95 \% \mathrm{CI})\end{array}$ & $\begin{array}{c}\text { Log-rank } \\
\text { P-value }\end{array}$ \\
\hline \multicolumn{5}{|c|}{ 1. Non-cancer parts ${ }^{c}$} \\
\hline \multirow[t]{2}{*}{ PR-GSK } & $<0.50$ & 77 & $95.3(77.3-113.3)$ & \\
\hline & $\geq 0.50$ & 76 & $91.3(76.7-106.0)$ & 0.529 \\
\hline \multirow[t]{2}{*}{ PR-PTEN } & $<1.87$ & 101 & $91.5(78.7-104.3)$ & \\
\hline & $\geq 1.87$ & 59 & $103.8(85.8-121.8)$ & 0.569 \\
\hline \multirow[t]{2}{*}{ PR-mTOR } & $<0.20$ & 94 & $101.9(86.8-117.1)$ & \\
\hline & $\geq 0.20$ & 59 & $84.7(68.3-101.1)$ & 0.235 \\
\hline \multirow[t]{2}{*}{ PR-p44 (ERK1) } & $<0.10$ & 20 & $53.4(38.6-68.2)$ & \\
\hline & $\geq 0.10$ & 134 & $98.4(85.9-110.8)$ & 0.425 \\
\hline \multirow[t]{2}{*}{ PR-p42 (ERK2) } & $<2.30$ & 104 & $101.8(87.8-115.7)$ & \\
\hline & $\geq 2.30$ & 46 & $79.4(56.2-102.5)$ & 0.187 \\
\hline \multirow[t]{2}{*}{ PR-ERK (1+2) } & $<3.50$ & 92 & $101.8(87.1-116.5)$ & \\
\hline & $\geq 3.50$ & 62 & $85(67.3-102.6)$ & 0.354 \\
\hline \multirow[t]{2}{*}{ PR-AKT } & $<0.01$ & 34 & $118.7(100.8-136.6)$ & \\
\hline & $\geq 0.01$ & 119 & $86.7(74.2-99.1)$ & $0.039^{\mathrm{e}}$ \\
\hline \multicolumn{5}{|l|}{ 2. Cancer parts ${ }^{\mathrm{c}}$} \\
\hline \multirow[t]{2}{*}{ PR-GSK } & $<0.60$ & 84 & $100.9(84.5-117.4)$ & \\
\hline & $\geq 0.60$ & 68 & $87.2(72.3-102.0)$ & 0.172 \\
\hline \multirow[t]{2}{*}{ PR-PTEN } & $<0.20$ & 50 & $105.5(90.8-120.3)$ & \\
\hline & $\geq 0.20$ & 102 & $90.7(74.4-107.1)$ & 0.188 \\
\hline \multirow[t]{2}{*}{ PR-mTOR } & $<0.50$ & 58 & $96.3(78.9-113.6)$ & \\
\hline & $\geq 0.50$ & 102 & $92.9(78.2-107.6)$ & 0.501 \\
\hline \multirow[t]{2}{*}{ PR-p44 (ERK1) } & $<0.89$ & 76 & $98.0(82.2-113.7)$ & \\
\hline & $\geq 0.89$ & 72 & $90.8(74.4-107.3)$ & 0.938 \\
\hline \multirow[t]{2}{*}{ PR-p42 (ERK2) } & $<2.40$ & 111 & $98.9(84.4-113.4)$ & \\
\hline & $\geq 2.40$ & 38 & 90.7 (68.5-112.9) & 0.747 \\
\hline \multirow[t]{2}{*}{ PR-ERK (1+2) } & $<2.50$ & 107 & $96.0(82.0-110.1)$ & \\
\hline & $\geq 2.50$ & 42 & $98.2(78.9-117.5)$ & 0.794 \\
\hline \multirow[t]{2}{*}{ PR-AKT } & $<0.63$ & 129 & $94.2(80.9-107.5)$ & \\
\hline & $\geq 0.63$ & 27 & $105.3(87.0-123.6)$ & 0.346 \\
\hline \multicolumn{5}{|c|}{ 3. Cancer parts/non-cancer parts ${ }^{\mathrm{d}}$} \\
\hline \multirow[t]{2}{*}{ PR-GSK } & $<0.95$ & 74 & $105.2(89.7-120.8)$ & \\
\hline & $\geq 0.95$ & 78 & $86.9(72.3-101.6)$ & 0.392 \\
\hline \multirow[t]{2}{*}{ PR-PTEN } & $<1.16$ & 104 & $98.3(84.9-111.6)$ & \\
\hline & $\geq 1.16$ & 47 & $91.3(72.1-110.5)$ & 0.670 \\
\hline \multirow[t]{2}{*}{ PR-mTOR } & $<2.48$ & 97 & $87.0(74.4-99.6)$ & \\
\hline & $\geq 2.48$ & 36 & $117.8(94.5-141.2)$ & 0.080 \\
\hline \multirow[t]{2}{*}{ PR-p44 (ERK1) } & $<0.61$ & 96 & 86.4 (73.1-99.7) & \\
\hline & $\geq 0.61$ & 50 & $115.1(96.0-134.2)$ & 0.070 \\
\hline \multirow[t]{2}{*}{ PR-p42 (ERK2) } & $<1.50$ & 114 & $90.4(77.5-103.2)$ & \\
\hline & $\geq 1.50$ & 29 & $111.0(89.9-132.1)$ & 0.239 \\
\hline \multirow[t]{2}{*}{ PR-ERK (1+2) } & $<0.84$ & 111 & $85.4(71.9-99.0)$ & \\
\hline & $\geq 0.84$ & 35 & $123.6(109.4-137.8)$ & $0.017^{\mathrm{e}}$ \\
\hline \multirow[t]{2}{*}{ PR-AKT } & $<1.10$ & 101 & $92.2(79.1-105.4)$ & \\
\hline & $\geq 1.10$ & 49 & $93.9(73.6-114.1)$ & 0.771 \\
\hline
\end{tabular}

${ }^{a}$ The expression level of a signaling protein in HepG2 cells was assigned as $1 \mathrm{HU}$ (HepG2 unit). The expression level of the protein in liver

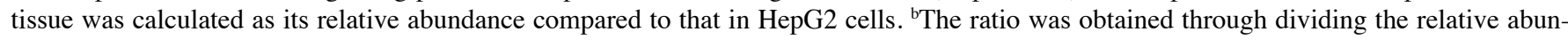

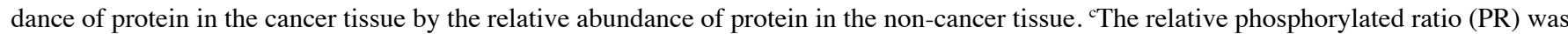
obtained through dividing the abundance of phosphorylated from by the abundance of the total form. ${ }^{\mathrm{d}}$ The ratio was obtained through dividing the relative phosphorylated ratio of protein in the cancer tissue by the relative phosphorylated ratio of protein in the non-cancer tissue. ${ }^{\mathrm{e} B e c a u s e}$ 5 cutoffs were experimentally tested for the smallest $\mathrm{P}$-value, $\mathrm{P}<0.05$ but $>0.01$ were considered borderline significant after Bonferroni correction of $\alpha$ error. ${ }^{\mathrm{f}} \mathrm{P}<0.01$ was considered statistical significant after Bonferroni correction. 

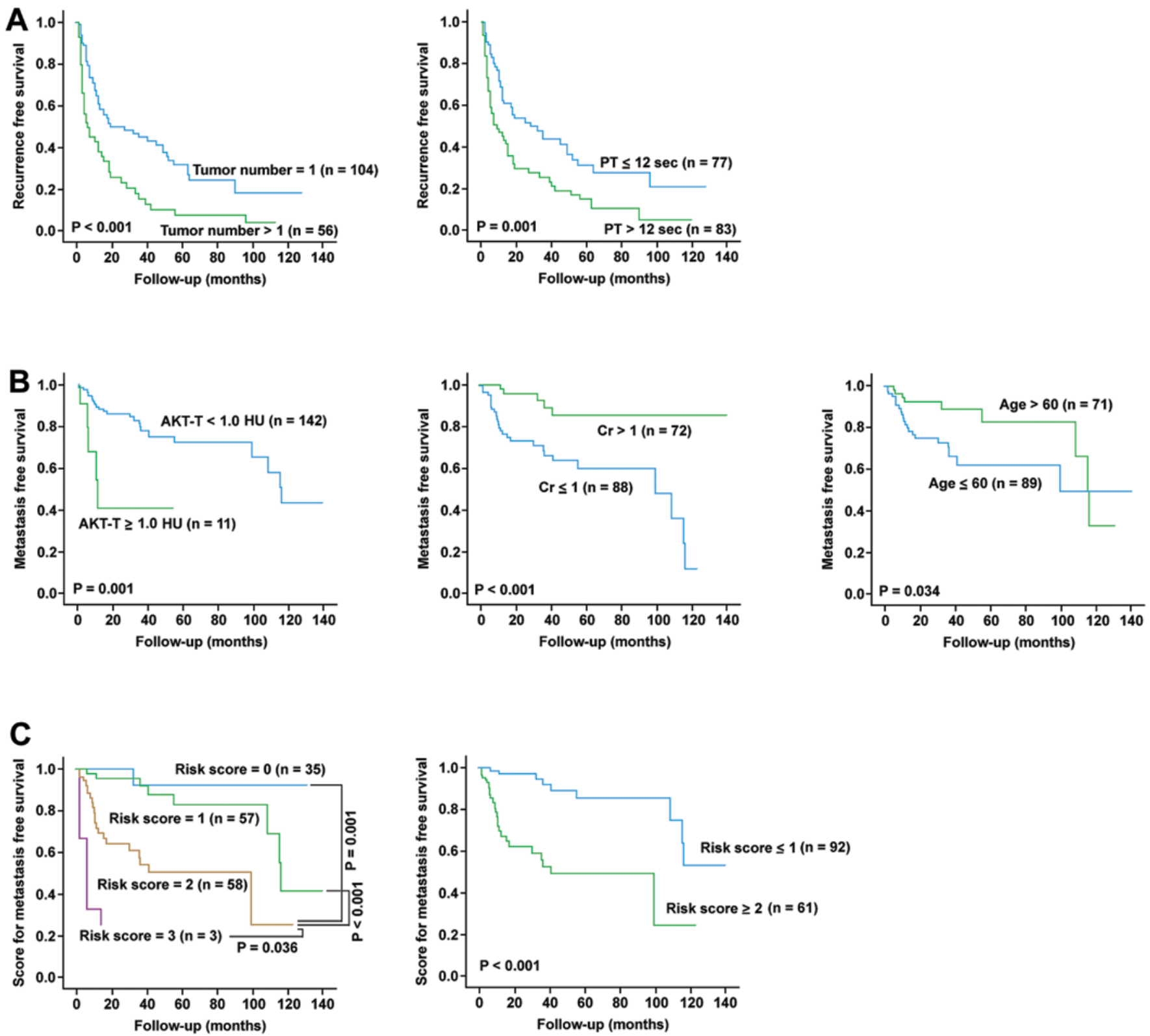

Figure 3. Kaplan-Meier analysis of the significant independent prognostic predictors derived from multivariate Cox proportional analysis including clinicopathological and molecular factors. (A) Predictors for LR-free recurrence. (B) Predictors for EHM-free survival. (C) Risk score assessment using the three EHM-free survival predictors.

whereas a higher ERK2-T level $(\geq 0.6 \mathrm{HU})$, a lower AKT-T $(<1.0 \mathrm{HU})$ level, and a higher GSK-T/N $(\geq 0.65)$ level significantly predicted a favorable EHM-free survival $(\mathrm{P}=0.005$, 0.001 and 0.008 , respectively).

No significant difference could be found when assessing the overall survival using these expression levels of signaling proteins (data not shown).

Multivariate analysis combining both clinical and molecular predictors. To understand whether the identified molecular predictors were helpful in survival prediction using clinicopathological factors, we combined the four identified molecular predictors (PR-mTOR-T, ERK2-T, AKT-T and GSK-T/N) and all clinicopathological factors for multivariate analysis (Table V). Cox proportional hazard model was used in this analysis. Univariate analysis revealed that microvascular invasion, tumor number, AFP, bilirubin, prothrombin time, AST, PR-mTOR-T, and ERK2-T significantly associated with the LR-free survival. After adjusted for other confounding factors, only tumor number $(\mathrm{P}=0.031)$ and prothrombin time $(\mathrm{P}=0.003)$ remained as independent predictors for LR-free survival. Kaplan-Meier analysis was performed for these two factors for verification (Fig. 3A).

On the other hand, univariate analysis revealed that age, prothrombin time, creatinine, AKT-T, ERK2-T and GSK-T/N significantly associated with EHM-free survival. After adjusted for other confounding predictors, only AKT-T $(\mathrm{P}=0.004)$, creatinine $(\mathrm{P}=0.001)$, and age $(\mathrm{P}=0.019)$ remained to be independent predictors for EHM-free survival. KaplanMeier analysis was performed for these three factors for verification (Fig. 3B). These three factors were then combined to estimate EHM-free survival using a risk score method 
Table V. Univariate and multivariate analysis of clinicopathologial parameters and signaling molecule expression levels for IRFS and EMFS in HCC patients.

\begin{tabular}{|c|c|c|c|c|c|}
\hline \multirow[b]{2}{*}{ Parameter } & \multirow[b]{2}{*}{$\begin{array}{l}\text { No. of } \\
\text { patients }\end{array}$} & \multicolumn{2}{|c|}{ IRFS } & \multicolumn{2}{|c|}{ EMFS } \\
\hline & & $\begin{array}{c}\mathrm{HR} \\
(95 \% \mathrm{CI})\end{array}$ & $\begin{array}{c}\text { Adjusted HR } \\
(95 \% \text { CI })\end{array}$ & $\begin{array}{c}\mathrm{HR} \\
(95 \% \mathrm{CI})\end{array}$ & $\begin{array}{l}\text { Adjusted HR } \\
\text { (95\% CI) }\end{array}$ \\
\hline
\end{tabular}

Age (years)

$\leq 60$

$>60$

71

$0.955(0.643-1.417)$

$0.446(0.207-0.961)^{\mathrm{a}}$

$0.382(0.171-0.851)^{\mathrm{a}}$

Gender

Female

Male

41

119

$1.109(0.705-1.7430$

$1.096(0.509-2.360)$

Cirrhosis

No

83

Yes

77

$1.165(0.787-1.726)$

$1.098(0.550-2.191)$

Alcoholism

No

115

Yes

$45 \quad 0.906(0.583-1.410)$

$0.861(0.397-1.865)$

Tumor characteristics

Microvascular invasion

No

113

Yes

Edmondson's grading

I-II

III-IV

59

101

$1.022(0.675-1.546)$

$1.480(0.687-3.187)$

Encapsulation

No

39

Yes

120

$0.706(0.455-1.095)$

$0.751(0.348-1.620)$

Tumor number

1

$>1$

104

56

$2.195(1.476-3.264)$

$1.735(1.052-2.861)^{a}$

$1.378(0.684-2.774)$

Largest tumor size

(diameter, $\mathrm{cm}$ )

$\leq 3$

40

120

$1.468(0.926-2.329)$

$1.357(0.610-3.018)$

Macrovascular invasion

No

147

Yes

$13 \quad 1.420(0.737-2.735)$

$2.621(0.993-6.919)$

Ascites

No

146

$14 \quad 1.613(0.835-3.116)$

$0.934(0.222-3.928)$

Serology

$\operatorname{AFP}(\mathrm{ng} / \mathrm{ml})$

$\leq 25$

51

$>25$

109

$\mathbf{1 . 6 6 3 ( 1 . 0 4 4 - 2 . 6 5 0})^{\mathrm{a}} \quad 1.611(0.950-2.729)$

$2.141(0.824-5.565)$

Albumin (g/dl)

$\leq 4.0$

106

$>4.0$

54

$0.777(0.513-1.176)$

$0.557(0.258-1.202)$ 
Table V. Continued.

\begin{tabular}{ccccccc}
\hline & & \multicolumn{3}{c}{ IRFS } & & \multicolumn{2}{c}{ EMFS } \\
\cline { 3 - 6 } \cline { 4 - 7 } Parameter & $\begin{array}{c}\text { No. of } \\
\text { patients }\end{array}$ & $\begin{array}{c}\text { HR } \\
(95 \% \mathrm{CI})\end{array}$ & $\begin{array}{c}\text { Adjusted HR } \\
(95 \% \mathrm{CI})\end{array}$ & & $\begin{array}{c}\text { HR } \\
(95 \% \mathrm{CI})\end{array}$ & $\begin{array}{c}\text { Adjusted HR } \\
(95 \% \mathrm{CI})\end{array}$ \\
\hline
\end{tabular}

\section{Bilirubin (mg/dl)}

$$
\leq 1.2
$$

$>1.2$

\section{1}

39

$1.657(\mathbf{1 . 0 6 9 - 2 . 5 7 1})^{\mathrm{a}} \quad 1.152(0.700-1.896)$

$1.844(0.846-4.016)$

Prothrombin time

( $\mathrm{sec})$

$\leq 12$ 77

$>12$

$1.975(1.325-2.944)^{b}$

$1.940(1.246-3.012)^{b} \quad 2.488(1.204-5.141)^{\mathrm{a}}$

$1.976(0.878-4.451)$

Creatinine $(\mathrm{mg} / \mathrm{dl})$

$\leq 1.0$

$>1.0$

$0.872(0.585-1.299)$

$0.187(0.972-0.486)^{b}$

$0.171(0.059-0.493)^{b}$

AST (U/1)

$\leq 36$

62

$>36$

98

$1.601(\mathbf{1 . 0 6 1 - 2 . 4 1 6})^{\mathrm{a}} \quad 1.295(0.835-2.009)$

$1.957(0.908-4.217)$

$\operatorname{ALT}(\mathrm{U} / \mathrm{l})$

$\leq 40$

72

$>40$

88

$1.372(0.924-2.037)$

$1.339(0.665-2.694)$

Anti-HCV

Negative

116

Positive

$44 \quad 1.298(0.839-2.008)$

$1.022(0.474-2.203)$

HBsAg

Negative

50

Positive

$0.882(0.579-1.346)$

$0.990(0.471-2.084)$

Signalling molecules

PR-mTOR-T

$\begin{array}{rr}<0.50 & 58 \\ \geq 0.50 & 102\end{array}$

$\mathbf{0 . 7 7 7}(\mathbf{0 . 6 3 8 - 0 . 9 4 5})^{\mathbf{b}} \quad 0.758(0.497-1.158) \quad 1.290(0.613-2.713)$

AKT-T

$<1.0 \mathrm{HU}$

142

$11 \quad 1.140(0.460-2.825)$

$4.529(1.702-12.050)^{b} 5.000(1.693-14.770)^{b}$

$\geq 1.0 \mathrm{HU}$

40

115

$0.770(\mathbf{0 . 6 1 4 - 0 . 9 6 6})^{\mathrm{a}} \quad 0.654(0.407-1.050)$

$\mathbf{0 . 3 5 6}(\mathbf{0 . 1 6 7 - 0 . 7 5 8})^{\mathrm{b}} \quad 0.516(0.231-1.1530)$

$<0.60 \mathrm{HU}$

126

GSK-T/N

$<0.65$

30

$1.024(0.797-1.317)$

$0.127(0.017-0.930)^{\mathrm{a}}$

$0.171(0.023-1.287)$

${ }^{\mathrm{a}} \mathrm{P}<0.05$; ${ }^{\mathrm{b}} \mathrm{P}<0.01 ; \mathrm{HR}$, hazard ratio; $\mathrm{CI}$, confidence interval.

(Fig. 3C). In this method, the presence of each unfavorable factor was given 1 risk-point. It was found that patients with risk score $\leq 1$ had significantly longer EHM-free survival $(\mathrm{P}<0.001)$.
Finally, to understand whether the differential sets of predictors for LR and EHM remained effective over time, we use the verification cohort which was collected in a later period of time for confirmation. It was found that prolonged 
prothrombin time $(\mathrm{P}=0.016)$ remained to be significantly associated with LR-free but not the EHM-free survival, whereas higher creatinine level $(\mathrm{P}=0.007)$ and higher AKT-T level $(\mathrm{P}=0.025)$ remained to be significantly associated with EHM-free but not LR-free survival.

\section{Discussion}

This study aimed to investigate whether postoperative LR and EHM in HCCs were governed by different sets of clinicopathological and molecular predictors. During the study, several interesting observations were made. Clustering analysis showed that in fact, the expression profiles of many protein factors in the cancer and non-cancer parts were generally concordant. This is consistent with the view that the para-neoplastic liver tissues (non-cancer parts) were already harboring adequate precancer changes, waiting for only a few final steps of molecular alterations to develop cancer (22).

Another interesting finding was that most of the effective predictors in this study were uncovered by comparing the levels of the cancer parts (-T) between patients. A number of predictors were generated by calculating the $\mathrm{T} / \mathrm{N}$ ratios and very few were found by comparing just the levels in the noncancer parts (-N). Since the cancer parts under analysis were the parts already being surgically removed, this observation suggested that HCC recurrence most likely developed through the same or similar oncogenic pathways used by the original (surgically removed) cancers. Therefore, the signaling protein levels in the removed cancer parts could serve as predictors for the next tumor development. On the other hand, the fact that the protein levels in the non-cancer parts could rarely serve as effective predictors implied that the accumulated molecular changes in the para-neoplastic/non-cancer tissues were not representative enough to illustrate the oncogenic pathways.

The most striking finding in the present study was that the LR and EHM were associated with different sets of predictors, clinicopathological or molecular. After adjusted for confounding factors, it was found that prothombin time prolongation and tumor number were the only two significant predictors for LR. Prothombin time prolongation remained effective as a predictor when tested in another cohort of patients collected from a different time-period. This result suggested that the functional reserve and thus the severity of long-standing liver damage was likely the major determinant for LR. On the other hand, EHM seemed to require activation of particular cellular pathways in the cancer tissues, in our study, the AKT mediated pathways. This was clearly demonstrated in the first part of the study when the mean expression levels were compared between the three presented prognostic groups (Fig. 2) and was also shown in the subsequent univariate and multivariate analysis. The most relevant interpretation of this result could be made according to the recently discovered association between the AKT mediated pathways and the epithelial to mesenchymal transition in various cancers including HCC (23-29). Thus, our present data supported the view that the epithelial to mesenchymal transition was needed for effective EHM of HCC cells. Another novel and striking finding was that a lower creatinine level was also needed for EHM, which was confirmed in the verification cohort. Additionally, in the training cohort, a younger age was a favorable factor for EHM. We speculated that a healthy host environment was needed for HCC metastasis, whereas the accumulation of body wastes, normally excreted by kidneys, could inhibit the metastasis process. This hypothesis could be verified using animal models in the future.

Of the significant signaling molecule predictors, increased PR-mTOR-T and ERK2-T levels were associated with a better postoperative prognosis, suggesting that ERK2 and phosphorylated mTOR played an inhibitory role for HCC tumor growth. This is against the general belief that mTOR and ERK2 play a growth promoting role in cancer cells. However, recent studies indicated that the TRAIL-mediated apoptosis in hepatoma and lung cancer cells was mediated by ERK2 activation $(30,31)$. On the other hand, although phosphorylated mTOR has been found to associate with poor prognosis in other cancers, its prognostic role in HCC has not been defined (32-36). Interestingly, in two of these reports $(34,36)$, only nuclear (but not cytoplasmic) phosphorylated mTOR was associated with poor prognosis of cancers. In the present study, we assayed the total expression levels of phosphorylated mTOR but did not differentiate the nuclear from cytoplasmic form. Because the relative volume of cytoplasm was much larger than that of nucleus, it could be speculated that the total amount of phosphorylated mTOR reversely correlated with the percentage of nuclear phosphorylated mTOR in HCC. If this hypothesis could be confirmed, the nuclear phosphorylated mTOR could also be associated with poor prognosis in HCC. Further study using immunohistochemistry analysis is needed to clarify this point.

In conclusion, this study revealed that postoperative LR and EHM of HCC were governed by two different sets of clinicopathological and molecular predictors, indicating the involvement of differential molecular pathways. LR preferentially arose from a liver of poorer functional reserve. On the other hand, EHM required participation of AKT-mediated signaling pathways, presumably associated with the endothelial to mesenchymal transition. In addition, a host environment with lower creatinine level, implying lower concentrations of kidney-excreting wastes, was also favorable for EHM.

\section{Acknowledgements}

We are indebted to numerous members of the Liver Research Center of Chang Gung Memorial Hospital for their help and encouragement. This study was supported by grants from Taiwan National Science Council (101-2325-B-182-010 and 101-2314-B-182-017-MY3).

\section{References}

1. Parkin DM, Bray F, Ferlay J and Pisani P: Estimating the world cancer burden: Globocan 2000. Int J Cancer 94: 153-156, 2001.

2. Perz JF, Armstrong GL, Farrington LA, Hutin YJ and Bell BP: The contributions of hepatitis $B$ virus and hepatitis $C$ virus infections to cirrhosis and primary liver cancer worldwide. J Hepatol 45: 529-538, 2006.

3. Tanaka K, Hirohata T, Takeshita S, Hirohata I, Koga S, Sugimachi K, Kanematsu T, Ohryohji $F$ and Ishibashi $\mathrm{H}$ : Hepatitis B virus, cigarette smoking and alcohol consumption in the development of hepatocellular carcinoma: a case-control study in Fukuoka, Japan. Int J Cancer 51: 509-514, 1992.

4. Bosch FX, Ribes J, Cleries R and Diaz M: Epidemiology of hepatocellular carcinoma. Clin Liver Dis 9: 191-211, 2005. 
5. El-Serag HB: Hepatocellular carcinoma: recent trends in the United States. Gastroenterology 127: S27-S34, 2004.

6. Sherman M: Hepatocellular carcinoma: epidemiology, risk factors, and screening. Semin Liver Dis 25: 143-154, 2005.

7. Park NH, Song IH and Chung YH: Chronic hepatitis B in hepatocarcinogenesis. Postgrad Med J 82: 507-515, 2006.

8. Chau GY, Wu CW, Lui WY, Chang TJ, Kao HL, Wu LH, King KL, Loong CC, Hsia CY and Chi CW: Serum interleukin-10 but not interleukin-6 is related to clinical outcome in patients with resectable hepatocellular carcinoma. Ann Surg 231: $552-558,2000$

9. Hsu YC, Fu HH, Jeng YM, Lee PH and Yang SD: Proline-directed protein kinase FA is a powerful and independent prognostic predictor for progression and patient survival of hepatocellular carcinoma. J Clin Oncol 24: 3780-3788, 2006.

10. Kitamoto M, Nakanishi T, Kira S, Kawaguchi M, Nakashio R, Suemori S, Kajiyama G, Asahara T and Dohi K: The assessment of proliferating cell nuclear antigen immunohistochemical staining in small hepatocellular carcinoma and its relationship to histologic characteristics and prognosis. Cancer 72: 1859-1865, 1993.

11. Kobayashi T, Kubota K, Takayama $\mathrm{T}$ and Makuuchi M: Telomerase activity as a predictive marker for recurrence of hepatocellular carcinoma after hepatectomy. Am J Surg 181: 284-288, 2001

12. Poon RT, Lau CP, Ho JW, Yu WC, Fan ST and Wong J: Tissue factor expression correlates with tumor angiogenesis and invasiveness in human hepatocellular carcinoma. Clin Cancer Res 9: 5339-5345, 2003

13. Poon RT, Ng IO, Lau C, Zhu LX, Yu WC, Lo CM, Fan ST and Wong J: Serum vascular endothelial growth factor predicts venous invasion in hepatocellular carcinoma: a prospective study. Ann Surg 233: 227-235, 2001.

14. Shen HM and Ong CN: Mutations of the p53 tumor suppressor gene and ras oncogenes in aflatoxin hepatocarcinogenesis. Mutat Res 366: 23-44, 1996.

15. Tsujita E, Taketomi A, Gion T, Kuroda Y, Endo K, Watanabe A, Nakashima H, Aishima S, Kohnoe S and Maehara Y: Suppressed MKP-1 is an independent predictor of outcome in patients with hepatocellular carcinoma. Oncology 69: 342-347, 2005.

16. Uenishi T, Kubo S, Yamamoto T, Shuto T, Ogawa M, Tanaka H, Tanaka S, Kaneda K and Hirohashi K: Cytokeratin 19 expression in hepatocellular carcinoma predicts early postoperative recurrence. Cancer Sci 94: 851-857, 2003

17. Lee TK, Poon RT, Yuen AP, Ling MT, Kwok WK, Wang XH, Wong YC, Guan XY, Man K, Chau KL and Fan ST: Twist overexpression correlates with hepatocellular carcinoma metastasis through induction of epithelial-mesenchymal transition. Clin Cancer Res 12: 5369-5376, 2006.

18. Zhu K, Dai Z, Pan Q, Wang Z, Yang GH, Yu L, Ding ZB, Shi GM Ke AW, Yang XR, Tao ZH, Zhao YM, Qin Y, Zeng HY, Tang ZY, Fan J and Zhou J: Metadherin promotes hepatocellular carcinoma metastasis through induction of epithelial-mesenchymal transition. Clin Cancer Res 17: 7294-7302, 2011.

19. Eisen MB, Spellman PT, Brown PO and Botstein D: Cluster analysis and display of genome-wide expression patterns. Proc Natl Acad Sci USA 95: 14863-14868, 1998.

20. Saldanha AJ: Java Treeview - extensible visualization of microarray data. Bioinformatics 20: 3246-3248, 2004.

21. Mazumdar M and Glassman JR: Categorizing a prognostic variable: review of methods, code for easy implementation and applications to decision-making about cancer treatments. Stat Med 19: 113-132, 2000
22. Trevisani F, Cantarini MC, Wands JR and Bernardi M: Recent advances in the natural history of hepatocellular carcinoma. Carcinogenesis 29: 1299-1305, 2008.

23. Chen R, Yang Q and Lee JD: BMK1 kinase suppresses epithelialmesenchymal transition through the Akt/GSK3beta signaling pathway. Cancer Res 72: 1579-1587, 2012.

24. Fenouille N, Tichet M, Dufies M, Pottier A, Mogha A, Soo JK, Rocchi S, Mallavialle A, Galibert MD, Khammari A, Lacour JP Ballotti R, Deckert M and Tartare-Deckert S: The epithelialmesenchymal transition (EMT) regulatory factor SLUG (SNAI2) is a downstream target of SPARC and AKT in promoting melanoma cell invasion. PLoS One 7: e40378, 2012.

25. Jiao $M$ and Nan KJ: Activation of PI3 kinase/Akt/HIF-1alpha pathway contributes to hypoxia-induced epithelial-mesenchymal transition and chemoresistance in hepatocellular carcinoma. Int J Oncol 40: 461-468, 2012.

26. Maseki S, Ijichi K, Tanaka H, Fujii M, Hasegawa Y, Ogawa T, Murakami S, Kondo E and Nakanishi H: Acquisition of EMT phenotype in the gefitinib-resistant cells of a head and neck squamous cell carcinoma cell line through Akt/GSK-3beta/snail signalling pathway. Br J Cancer 106: 1196-1204, 2012.

27. Ogunwobi OO and Liu C: Hepatocyte growth factor upregulation promotes carcinogenesis and epithelial-mesenchymal transition in hepatocellular carcinoma via Akt and COX-2 pathways. Clin Exp Metastasis 28: 721-731, 2011.

28. Ogunwobi OO, Wang T, Zhang L and Liu C: Cyclooxygenase-2 and Akt mediate multiple growth-factor-induced epithelialmesenchymal transition in human hepatocellular carcinoma. J Gastroenterol Hepatol 27: 566-578, 2012.

29. Wen W, Ding J, Sun W, Fu J, Chen Y, Wu K, Ning B, Han T, Huang L, Chen C, Xie D, Li Z, Feng G, Wu M, Xie W and Wang H: Cyclin G1-mediated epithelial-mesenchymal transition via phosphoinositide 3-kinase/Akt signaling facilitates liver cancer progression. Hepatology 55: 1787-1798, 2012.

30. Frese S, Pirnia F, Miescher D, Krajewski S, Borner MM, Reed JC and Schmid RA: PG490-mediated sensitization of lung cancer cells to Apo2L/TRAIL-induced apoptosis requires activation of ERK2. Oncogene 22: 5427-5435, 2003.

31. Liang X, Du J, Liu Y, Cui M, Ma C, Han L, Qu Z, Zhang Z, Sun Z, Zhang L, Chen YH and Sun W: The hepatitis B virus protein MHBs(t) sensitizes hepatoma cells to TRAIL-induced apoptosis through ERK2. Apoptosis 12: 1827-1836, 2007.

32. Bakarakos P, Theohari I, Nomikos A, Mylona E, Papadimitriou C, Dimopoulos AM and Nakopoulou L: Immunohistochemical study of PTEN and phosphorylated mTOR proteins in familial and sporadic invasive breast carcinomas. Histopathology 56: 876-882, 2010

33. Hirashima K, Baba Y, Watanabe M, Karashima R, Sato N, Imamura Y, Hiyoshi Y, Nagai Y, Hayashi N, Iyama K and Baba H: Phosphorylated mTOR expression is associated with poor prognosis for patients with esophageal squamous cell carcinoma. Ann Surg Oncol 17: 2486-2493, 2010.

34. Li N,Zhong M and Song M: Expression of phosphorylated mTOR and its regulatory protein is related to biological behaviors of ameloblastoma. Int J Clin Exp Pathol 5: 660-667, 2012.

35. Ueng SH, Chen SC, Chang YS, Hsueh S, Lin YC, Chien HP, Lo YF, Shen SC and Hsueh C: Phosphorylated mTOR expression correlates with poor outcome in early-stage triple negative breast carcinomas. Int J Clin Exp Pathol 5: 806-813, 2012.

36. Yoshida Y, Kurokawa T, Horiuchi Y, Sawamura Y, Shinagawa A and Kotsuji F: Localisation of phosphorylated mTOR expression is critical to tumour progression and outcomes in patients with endometrial cancer. Eur J Cancer 46: 3445-3452, 2010. 